Brazilian Journal

of Chemical

\title{
SEPARATION OF ETHANOL AND WATER BY EXTRACTIVE DISTILLATION WITH SALT AND SOLVENT AS ENTRAINER: PROCESS SIMULATION
}

\author{
I. D. Gil", A. M. Uyazán, J. L. Aguilar, G. Rodríguez and L. A. Caicedo \\ Departamento de Ingeniería Química, Universidad Nacional de Colombia \\ Ciudad Universitaria, Phone: +(57) (1) 3165672, Fax: +(57) (1)-3165617, \\ Carrera 30 45-03, Bogotá D.C., Colombia \\ E-mail: idgilc@unal.edu.co
}

(Received: February 1, 2007 ; Accepted : November 6, 2007)

\begin{abstract}
The aim of this work is to simulate and analyze an extractive distillation process for azeotropic ethanol dehydration with ethylene glycol and calcium chloride mixture as entrainer. The work was developed with Aspen Plus ${ }^{\circledR}$ simulator version 11.1. Calculation of the activity coefficients employed to describe vapor liquid equilibrium of ethanol - water - ethylene glycol - calcium chloride system was done with the NRTL-E equation and they were validated with experimental data. The dehydration process used two columns: the main extractive column and the recovery column. The solvent to feed molar ratio $\mathrm{S} / \mathrm{F}=0.3$, molar reflux ratio $\mathrm{RR}=0.35$, number of theoretical stages $\mathrm{Ns}=18$, feed stage $\mathrm{Sf}=12$, feed solvent stage $\mathrm{SS}=3$, and feed solvent temperature $\mathrm{TS}=80{ }^{\circ} \mathrm{C}$, were determined to obtain a distillate with at least $99.5 \%$ mole of ethanol. A substantial reduction in the energy consumption, compared with the conventional processes, was predicted by using ethylene glycol and calcium chloride as entrainer.

Keywords: Simulation; Extractive distillation; Ethylene glycol; Calcium chloride.
\end{abstract}

\section{INTRODUCTION}

Anhydrous ethanol is widely used in chemical industry as powerful solvent and as raw material or intermediate in chemical synthesis of esters, organic and cyclic compound chains, detergents, paints, cosmetics, aerosols, perfumes, medicine and food, among others. Besides, ethanol and gasoline mixtures can be used as fuels reducing environmental contamination and anhydrous ethanol addition improves octane index (Barba et al., 1985; Black, 1980; Chianese and Zinnamosca, 1990; Meirelles et.al., 1992). Several processes for ethanol dehydration are used such as heterogeneous azeotropic distillation, which uses different solvents such as benzene, pentane and cyclohexane; extractive distillation with solvents and salts as separating agents (Fu, 2004a,b); adsorption with molecular sieves and processes that include the use of pervaporation membranes (Black, 1980; Lynn and Hanson, 1988; Jacques et al., 1999; Pinto et al., 2000; Ulrich and Pavel, 1988). All these processes have had industrial application but some are no longer in use due to the high operating costs, operative problems and high energy consumption. In the case of gasoline as separating agent it reverses ethanol-water volatility, causing water to be removed as the top product and ethanol, mixed with solvent, to be withdrawn as the bottom product. Water is completely absent in the bottom product, it is withdrawn in the top mixed with some traces of ethanol and lighter hydrocarbons. For this reason, the

*To whom correspondence should be addressed 
ethanol produced by such a process can be used only as gasohol and for this particular process the amount of solvent is high and can only be applied with a petroleum refinery (Chianese and Zinnamosca, 1990).

Extractive distillation is a partial vaporization process, in the presence of a non-volatile and high boiling point separating mass agent that it is usually called entrainer or separating agent, which is added to the azeotropic mixture to alter the relative volatility of the key component without additional azeotrope formation (Perry et al., 1992; Black and Distler, 1972). Generally, entrainer is fed in the upper part of the column, above the feed stream and it remains in a considerable concentration in the liquid phase along the column. It is withdrawn as a bottom product with one of the components that are being separated and it is sent to a second regeneration column operated under vacuum. The most common solvents used in extractive distillation are glycols (Perry et al., 1992; Meirelles et al., 1992), glycerol (Lee and Pahl, 1985), gasoline (Chianese and Zinnamosca, 1990) and for the case of saline extractive distillation, acetate and inorganic salts such as: $\mathrm{CaCl}_{2}, \mathrm{AlCl}_{3}, \mathrm{KNO}_{3},\left(\mathrm{CuNO}_{3}\right)_{2} 3 \mathrm{H}_{2} \mathrm{O}$, $\mathrm{Al}(\mathrm{NO})_{3} 9 \mathrm{H}_{2} \mathrm{O}, \mathrm{K}_{2} \mathrm{CO}_{3}$ (Barba et al., 1985; Furter, 1992; Ligero and Ravagnani, 2003; Llano and Aguilar, 2003; Pinto et al. 2000; Schmit and Vogelpohl, 1983).

Extractive distillation with salts and solvents as separating agents turns up as a new possibility to obtain high purity products. This process combines the traditional extractive distillation with the "salt effect" principle. With this combined method, it is possible to solve several eventual problems of transport, dissolution, corrosion and obstruction found when only salt is used as separating agent. In addition, it has the following characteristics (Rongqi and Zhanting, 1999):

- Allows continuous operation because of the high efficiency and the low waste of solvent.

- A high purity product can be obtained.

- The relative volatility of the ethanol-water system is increased, compared to the effect produced by each of independent agents.

- Improves the solvent performance. Compared with normal extractive distillation, the quantity of the solvent to recycle is reduced to its fourth or fifth, the number of theoretical stages required can be reduced to its third, as well as energy consumption.

There is one industrial packing column reported by $\mathrm{Fu}(2004 b)$ used to separate ethanol-water mixtures, which was simulated and the results were in good agreement with industrial data. Also, some laboratory studies have been done to separate nonpolar systems, such as $\mathrm{C} 4$ hydrocarbon mixtures and polar systems, such as ethanol-water, from which it is possible to reach to some conclusions about the efficiency of separating agents in the processes (Zhigang et al., 2002). Analysis of ethanol-water system was focused on obtaining experimental data of the vapor-liquid equilibrium for the system ethanol-water-ethylene glycol-calcium chloride, as well as on performing experimental runs in the laboratory that have allowed to establish some operating parameters, reported by Rongqi and Zhanting (1999). One of the results to enhance from this work is that the separating agent (salt-solvent mixture) was recovered in a later stage of the separation and recycled to the process, not being necessary to separate the salt and the solvent.

The aim of this work is to study and establish industrial operating conditions for the extractive distillation of ethanol using ethylene glycol-calcium chloride mixture as entrainer.

\section{METHODOLOGY}

\section{Problem Definition}

All the work was developed using Aspen Plus Simulator, version 11.1. Activity coefficient calculations for the mixture were made with the NRTLE thermodynamic model for electrolytes systems, which was validated with experimental data reported in previous works (Zhigang et al. 2002) using Aspen Split Simulator. In Fig. 1 the flowsheet of the system on which the simulation was run is shown.

The arrangement has a first dehydration column to which an alcoholic solution, which is near to the azeotropic composition, is fed on one of the middle stages; and separating agent on one of the upper stages. As overhead product, in the dehydration column, alcohol with a $99.5 \%$ molar concentration is obtained, and as bottom product a mixture of waterentrainer is withdrawn. This mixture is taken to a second regeneration column, in which vacuum is applied in order to separate water from the separating agent and recycle it later to the dehydration process, while water with some content of ethanol (stream 5, Figure 1) is recycled back to the rectification step located in an upstream zone of overall alcohol process production. 


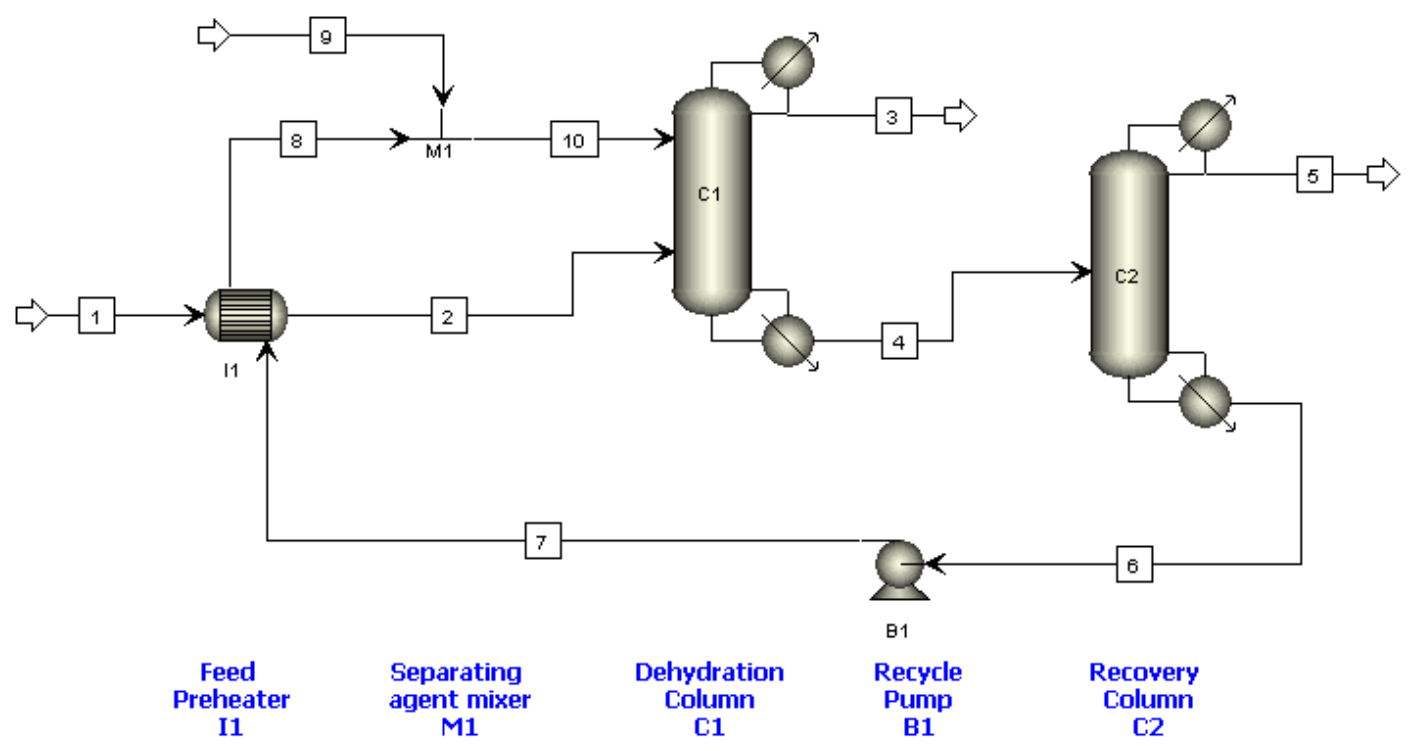

Figure 1: Flowsheet for the extractive distillation using salt and solvent.

\section{Process Simulation}

\section{a) Thermodynamic Model}

Initially, the thermodynamic model was validated calculating the vapor-liquid pseudo-binary equilibrium in the Aspen Split simulator by Aspen Tech. In Fig. 2 the curve for the vapor-liquid pseudobinary equilibrium $(101.3 \mathrm{kPa})$ for ethanol-waterethylene glycol-calcium chloride system is shown, plotted by the simulator with the NRTL-E thermodynamic model, together with experimental data reported by Zhigang et al. (2002).

\section{b) Configuration}

In this work the reflux ratio, number of theoretical stages required for the separation, azeotropic mixture and separating agent feeding stages, feed temperature of separating agent, solvent to feed molar ratio and salt concentration in the solvent were evaluated. Operating pressure in extractive column was set at $1 \mathrm{~atm}$. The thermal condition for the azeotropic feed (stream 2) was saturated liquid, as in other works (Meirelles et al., 1992; Ligero and Ravagnani, 2003; Chianese and Zinnamosca, 1990); in order to establish a comparative pattern of the process from the energy consumption viewpoint with respect to other technologies.

In Fig. 1 a flowsheet for the simulation of extractive distillation system is shown. The extractive distillation column $(\mathrm{C} 1)$ and the solvent regeneration column $(\mathrm{C} 2)$ are modeled. Besides this, a heat recovery scheme is proposed. This recovered heat is provided by the solvent recycle stream (7), which is used to preheat the azeotropic feed (1).
Sensitivity analyses were made and it was possible to visualize the effect of two variables on a specific design condition by observing the response surface plots. The efficient operating criteria considered were: energy consumption of the reboilers for each column and the distillate composition in the extractive column, which should be $99.5 \%$ molar of ethanol. The mole recovery of ethanol present in the azeotropic mixture was over $97.5 \%$. In the recovery column the main restriction was the purity of the solvent obtained at the bottom, which was expected to be water free and to be then recycled to the extractive column without affecting the purity of the ethanol recovered. In addition, the bottom temperature should be lower than $150^{\circ} \mathrm{C}$ to avoid thermal degradation of the solvent (Meirelles et al., 1992; Stupiello, 2003). For this reason the column pressure was fixed to reach that condition.

The inlet streams for the process were: azeotropic ethanol and a mixture of ethylene glycol with purity higher than $99.8 \%$ molar and calcium chloride in a concentration near to $0.1 \mathrm{~g} / \mathrm{ml}$ of ethylene glycol. The basis for the simulation was $100 \mathrm{kmol} / \mathrm{h}$ of azeotropic ethanol as saturated liquid, condition that was used as a starting point in previous works (Meirelles et al. 1992; Rongqi and Zhanting, 1999). The separating agent was the mixture ethylene glycol-calcium chloride with a flow rate of 30 $\mathrm{kmol} / \mathrm{h}$ in solvent base at $80^{\circ} \mathrm{C}$. Other initial input values were:

- Theoretical stages number for extractive column: 22 .

- Top stage: 1

- Feed stage: 12.

- Solvent feed stage: 3.

- Reflux Ratio: 0.6.

- Solvent to feed (S/F) molar ratio: 0.3. 


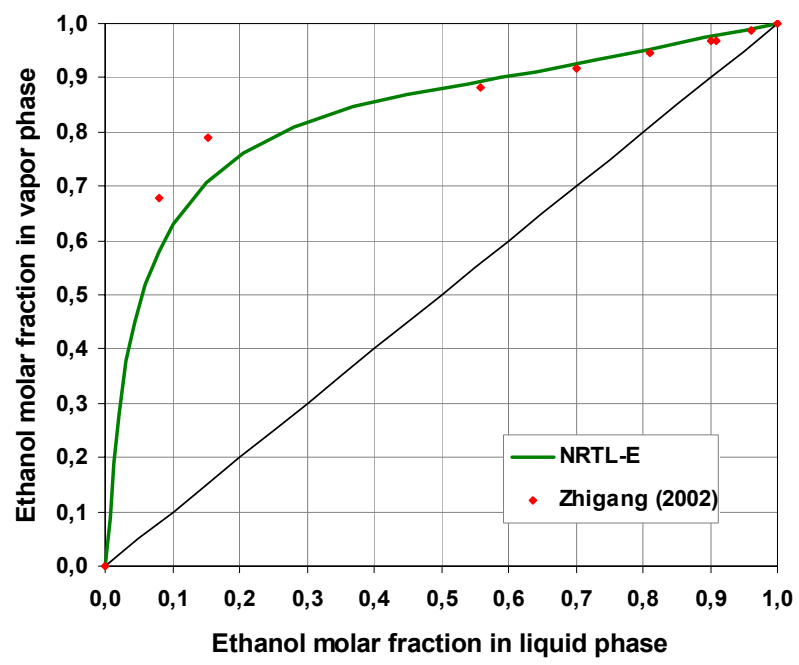

Figure 2: Pseudo-binary ethanol-water-ethylene-glycol-calcium chloride equilibrium, Pseudo-binary ethanol-water-ethylene-glycol-calcium chloride equilibrium,

\section{RESULTS AND DISCUSSION}

\section{Effect of Azeotropic Mixture Feed Stage and Number of Theoretical Stages}

In Fig. 3 the effect of feed stage and number of theoretical stages on the molar composition of distillate in the extractive column is presented. It can be observed that for stage numbers above 16 the values for molar fraction of ethanol in distillate and energy consumption remain approximately constant for any azeotropic feed stage.

For values below 16 only some combinations of feed stage and number of theoretical stages allow to obtain $99.5 \%$ molar ethanol, therefore, in order to work in a safe region of the design and taking into account approximately constant behavior, 18 is the number of stages chosen for the column. In the same way, it is observed that, as the azeotropic feed stage is closer to the reboiler, the molar fraction of ethanol in distillate increases, and so does the energy consumption, this shows that the biggest separation takes place in the rectifying section and in higher ethanol content zones. This agrees with the vaporliquid pseudo-binary equilibrium curve reported, which presents a closer approach to the $45^{\circ}$ in the region of high ethanol content and a more ideal behavior in low ethanol concentration zone, in which the separation is easier and only few theoretical stages are required to make the separation. Stage 12, then, was chosen in order to obtain the ethanol composition required in the distillate and decrease the reboiler energy consumption.

\section{Effect of Separating Agent Feed Stage}

The results shown in Fig. 4(a) allow establishing a maximum in the distillate molar fraction for all the tested conditions when the solvent is fed on the third stage. The two top bands define a favorable composition zone, which is not greatly affected by changes in the reflux ratio. However, the value of this ratio must be low to avoid energy wastes during operation. Reflux ratios in a range of 0.3-0.4 reach composition requirements with lower energy consumption in the reboiler.

As the solvent feed stage approaches to the condenser ethanol content increases up to a maximum, after which it decreases. This decrease is due to a vaporization of the ethylene glycol entering in the column, which becomes part of the vapor that flows up to the condenser and that is withdrawn as distillate. In the hydraulic system of the column there is also the possibility that part of the ethylene glycol is dragged by the up going flow vapor, important aspect to take into account in mechanical design of the equipment (implementing for example, mist eliminators). Fig. 4(b) shows that the change in reflux ratio has a greater effect on the reboiler energy consumption than that of the solvent feed stage. 


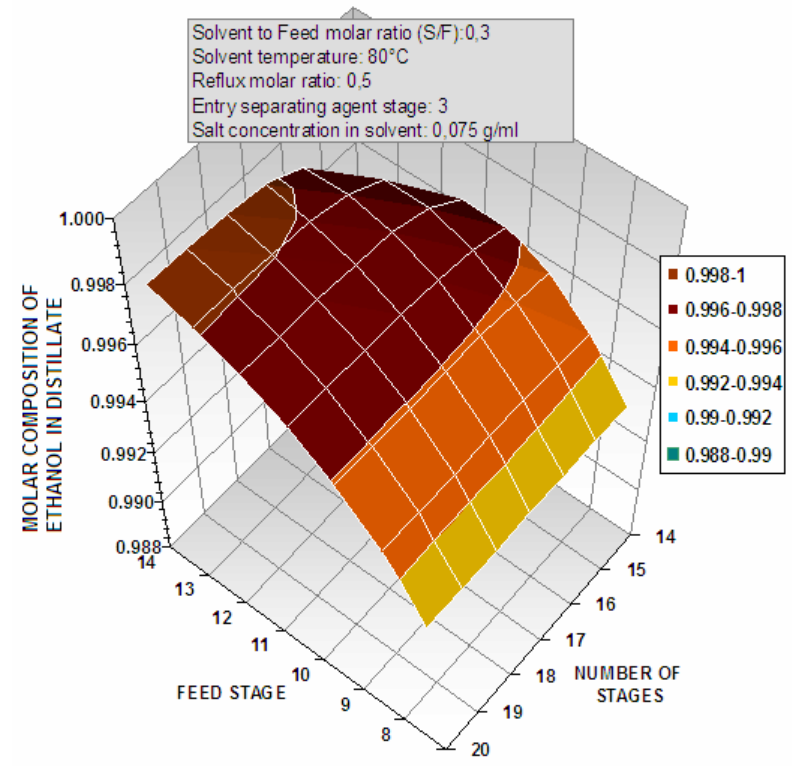

(a)

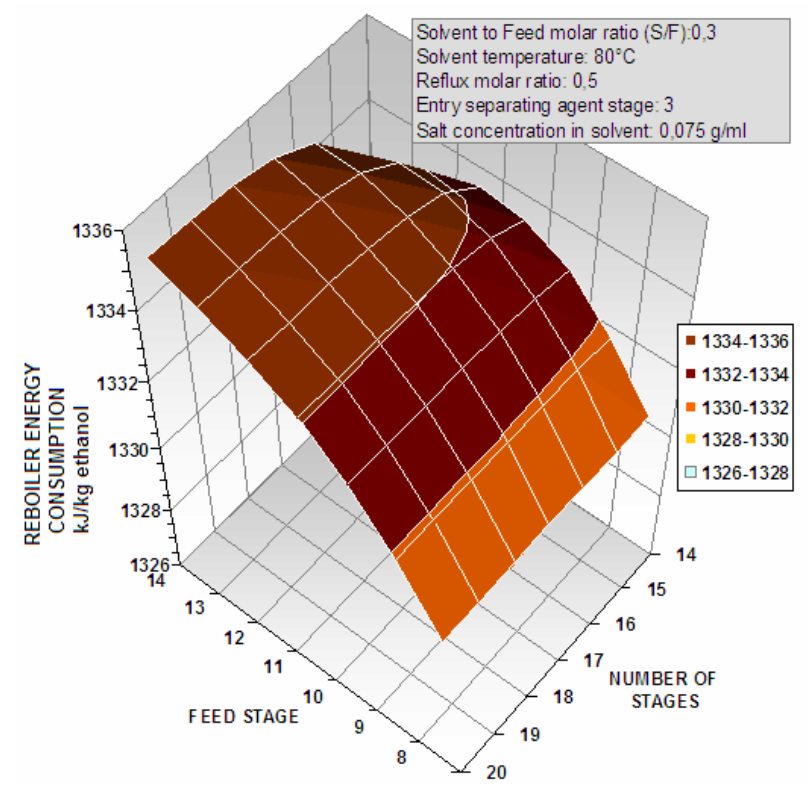

(b)

Figure 3: Effect of number of theoretical stages and feed stage of the distillation column with ethylene glycol and calcium chloride on : (a) distillate composition and (b) reboiler energy consumption

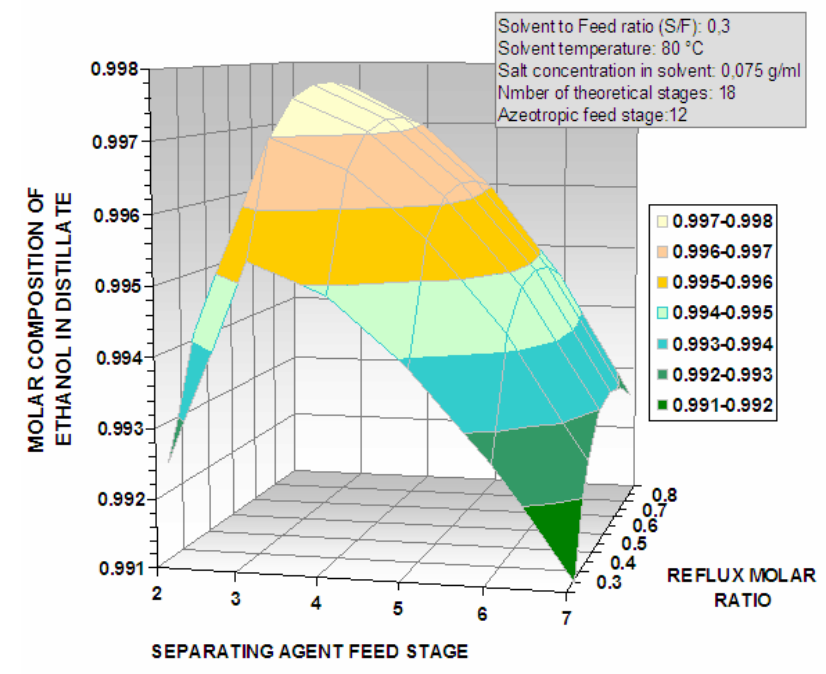

(a)

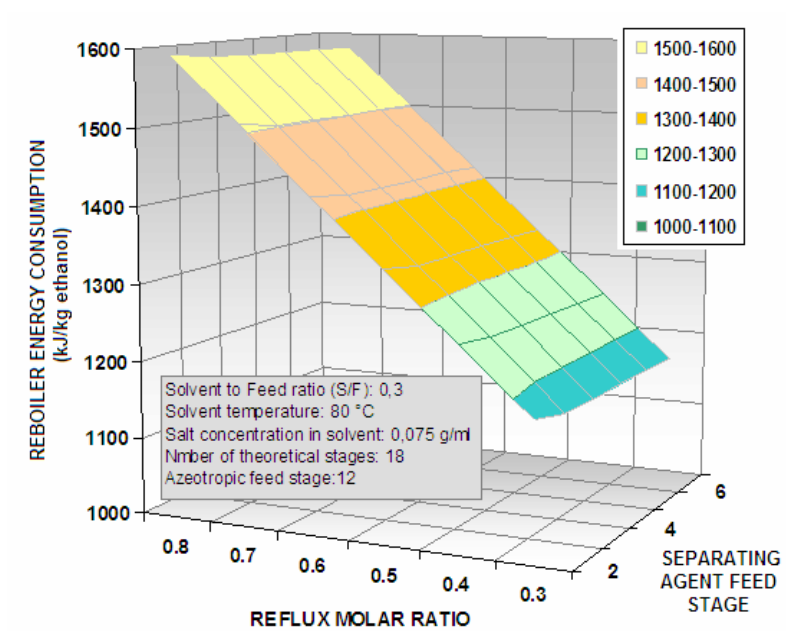

(b)

Figure 4: Effect of molar reflux ratio and solvent feed stage of the distillation column with ethylene glycol and calcium chloride on : (a) distillate composition and (b) reboiler energy consumption

\section{Effect of Salt Concentration in the Solvent}

The experimental data of the vapor-liquid equilibrium mixture reported by Zhigang et al. (2002), used to fit the NRTL-E model, use a calcium chloride concentration of $0.1 \mathrm{~g} / \mathrm{ml}$ of ethylene glycol. For this work this value has been chosen as a starting point, but two lower concentrations $(0.05$ and 0.075 $\mathrm{g}$ of $\mathrm{CaCl}_{2} / \mathrm{ml}$ of ethylene glycol) were used with the aim of establishing the minimal quantity of salt required for this separation.

The results show that when calcium chloride concentration increases, distillate composition and energy consumption also increases (Fig. 5). Moreover, comparing this operation with that in which only ethylene glycol was used (Meirelles et al., 1992), it is observed that a lower $\mathrm{S} / \mathrm{F}$ ratio is required for the separation, and the increase in the distillate purity is higher for the 0.05 and $0.075 \mathrm{~g}$ of $\mathrm{CaCl}_{2} / \mathrm{ml}$ of ethylene glycol change than that of 0.075 and $0.1 \mathrm{~g}$ of $\mathrm{CaCl}_{2} / \mathrm{ml}$ of ethylene glycol change. The advantage of using salt in solvent is that number of theoretical stages required for the separation and energy consumption are lower than the obtained in previous studies using only ethylene glycol as separating agent. The diminishment in energy consumption for the reboiler is explained by the effect that the addition of salt has on the mixture, since the quantity of solvent used is less than the one used in the operation without salt. 


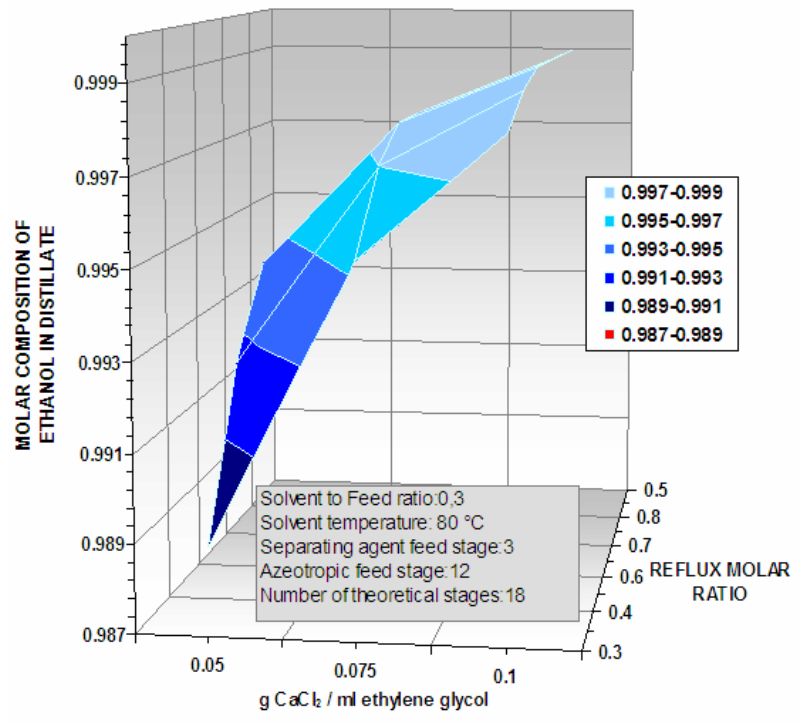

(a)

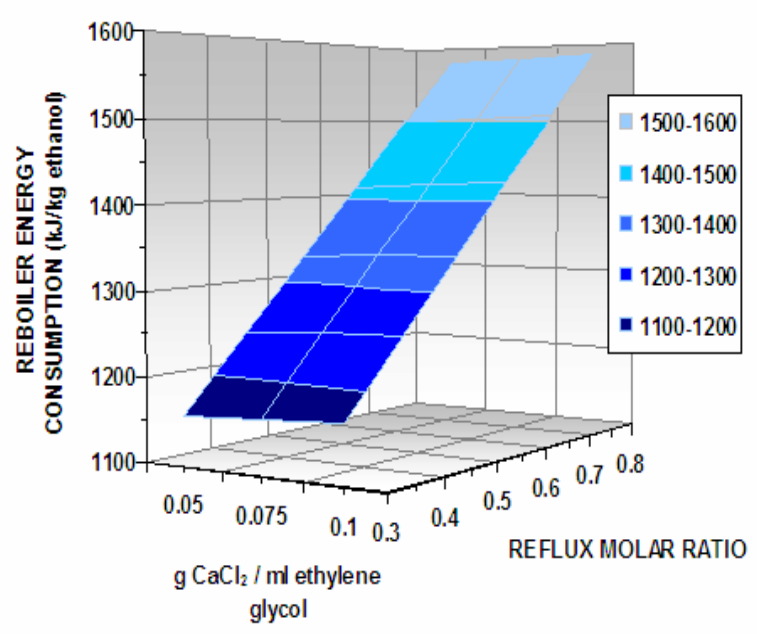

(b)

Figure 5: Effect of molar reflux ratio and Calcium Chloride concentration on the extractive distillation column with ethylene glycol and calcium chloride on:

(a) distillate composition and (b) energy consumption in the boiler.

Addition of salt, together with the low reflux ratio, does not lead to higher energy consumption, and as it is observed, for fixed reflux ratios, the slope respect to the salt concentration axis is near to zero. Taking into account these criteria, the salt concentration was fixed at $0.075 \mathrm{~g}$ salt $/ \mathrm{ml}$ of solvent, in order to obtain the lowest energy consumption.

\section{Effect of Solvent to Feed Ratio (S/F)}

Solvent to feed ratio $(\mathrm{S} / \mathrm{F})$ causes a direct effect on the distillate purity. Sensitivity analyses, plotted in Fig. 6, show that increasing $\mathrm{S} / \mathrm{F}$ ratio it is possible to have an important improvement in the overhead product quality, without considerably affecting energy consumption. At a constant reflux ratio, for different values of S/F within the interval 0.3-0.4, the energy consumption increased in $3.8 \%$. In the same way, maintaining the $\mathrm{S} / \mathrm{F}$ ratio at 0.3 , and increasing values of the reflux ratio until a distillate composition equivalent to the one obtained in the previous variation is reached; the increase in energy consumption was $26.6 \%$. Consequently, the reflux ratio must be operated in the lowest possible value, so the ratio $\mathrm{S} / \mathrm{F}$ can be manipulated to reach the distillate composition without high energy consumption, and reminding that high $\mathrm{S} / \mathrm{F}$ ratios increase the energy consumption in reboiler of the regeneration column.

Explanation for the predominance of the S/F ratio effect over reflux ratio effect on the distillate composition is that a higher amount of solvent leads to a better separation compared to the one obtained with a higher reflux ratio. Also, increasing the reflux ratio leads to the dilution of the solvent diminishing its effect. High $\mathrm{S} / \mathrm{F}$ ratios are needed since a high quantity of solvent will make the dilution effect caused by high refluxes negligible. Rising S/F and reflux ratios increase the liquid flow in the column. Both situations imply an increase in energy consumption. However, the liquid brought by reflux must be vaporized, opposite to the solvent restriction of remaining in liquid phase on column. This offers an explanation for the bigger effect caused by reflux ratio.

\section{Effect of Feed Solvent Temperature}

Temperature of the solvent into the extractive distillation column has an important effect on the distillate composition and the reboiler energy consumption, this effect depends on the reflux ratio. As it can be observed in Fig. 7, using high solvent temperatures demands high reflux ratios to reach a specified separation. This occurs because, as temperature of the solvent is increased, part of the water found in the stage vaporizes, increasing the content of water in the distillate and decreasing its purity. Then increasing reflux ratio is necessary to compensate this effect. In conclusion, low reflux operations need solvent fed at temperatures between 70 and $80^{\circ} \mathrm{C}$ to keep the distillate purity. Analyzing in parallel the surfaces showing the effect on composition and energy consumption, it is found that the least energy demand corresponds to low temperatures and low reflux ratios. 


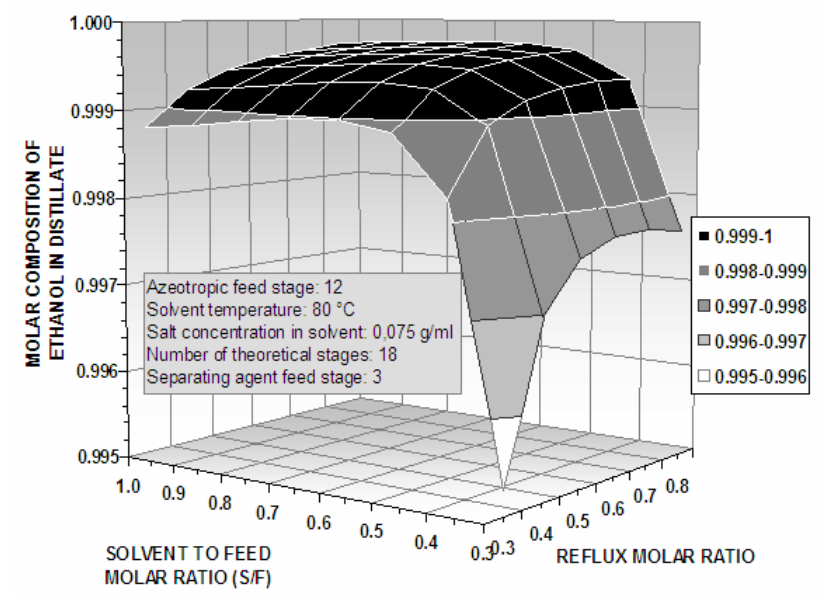

(a)

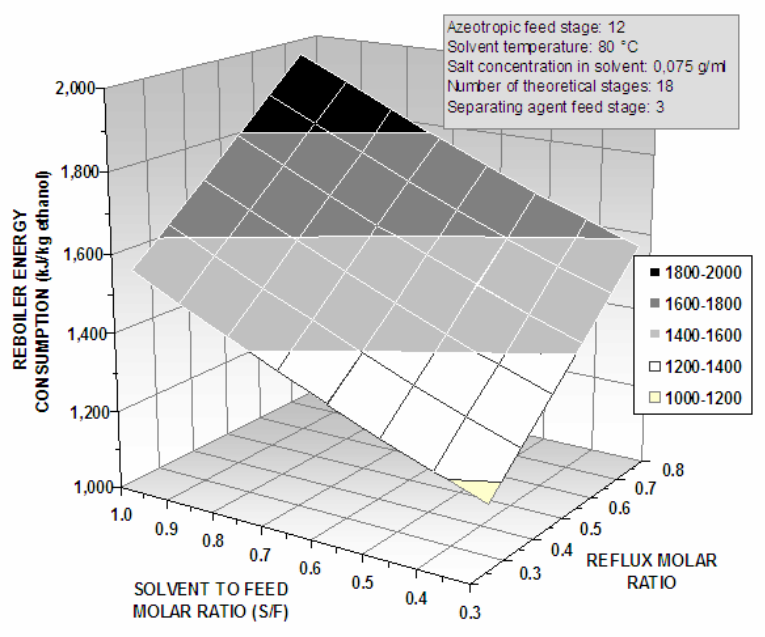

(b)

Figure 6: Effect of molar reflux ratio and of S/F molar ratio on the extractive distillation column with ethylene glycol and calcium chloride on: (a) distillate composition and (b) reboiler energy consumption .

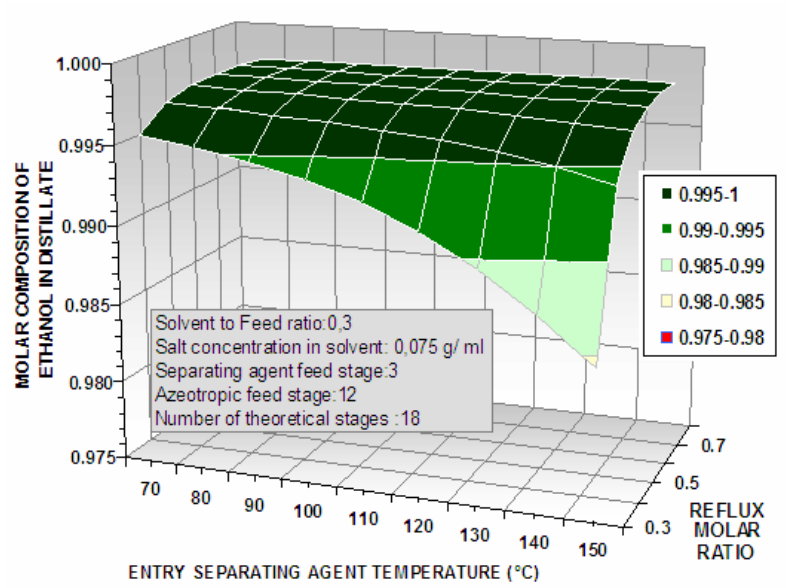

(a)

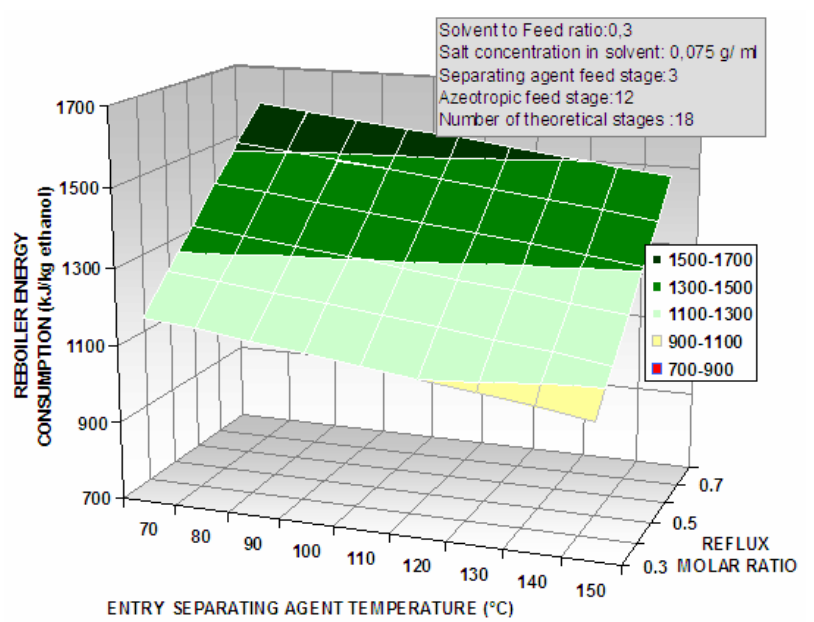

(b)

Figure 7: Effect of molar reflux ratio and entry separating agent temperature in the extractive distillation column with ethylene glycol and calcium chloride on: (a) distillate composition and (b) reboiler energy consumption.

\section{Effect of Reflux Ratio}

The effect of the reflux ratio on the distillate composition is shown in all sensitivity analyses. For a wide range of reflux ratio, only small variations in ethanol purity were observed. The increase in the reflux ratio leads to high contents in the distillate up to a maximum, which decreases later for reflux ratios higher than 0.8 , in all cases. This behavior is due to the solvent dilution into the column, condition that diminishes its effect on the relative volatility of the mixture ethanol-water. For this reason, it is necessary to compensate content diminishment by increasing the ratio $\mathrm{S} / \mathrm{F}$.

A summary of the operating conditions obtained for extractive and recovery distillation columns is shown in Table 1 and the corresponding material balance for the entire process is shown in Table 2 according to the information provided in Figure 1. It can be observed that the reflux ratio must be low, as well as the amount of solvent used in the separation. In the same way, it is important to notice that the energy recovered in stream 7 represents almost $50 \%$ of the heat supplied to the regeneration column, what shows that the heat recovering scheme proposed is interesting and can make this process competitive with the current processes. Also, it can be noticed that the stream 3 has a low content of ethylene glycol which limits the use of this anhydrous ethanol to the fuels application, however many other applications could be available if some adjustments in operating conditions and number of theoretical stages in extractive column are made. Finally, the content of ethanol obtained in stream 5 makes possible to recycle this mixture to the preliminary purification steps of ethanol located in the distillation section of a typical alcohol plant. 
Table 1: Operating conditions obtained for the two columns

\begin{tabular}{|c|c|c|}
\hline Operating variable & Extractive Column & Recovery Column \\
\hline Feed flow $(\mathrm{kmol} / \mathrm{h})$ & 100 & 44 \\
\hline Solvent flow $(\mathrm{kmol} / \mathrm{h})$ & 30 & ------- \\
\hline Distillate flow $(\mathrm{kmol} / \mathrm{h})$ & 86.864 & 13.70 \\
\hline Molar fraction of ethanol in distillate & 0.9963 & -------- \\
\hline Feed temperature $\left({ }^{\circ} \mathrm{C}\right)$ & 78.18 & 120.98 \\
\hline Solvent temperature $\left({ }^{\circ} \mathrm{C}\right)$ & 80 & ------- \\
\hline Molar reflux ratio & 0.35 & 0.25 \\
\hline Number of theoretical stages & 18 & 11 \\
\hline Feed stage & 12 & 6 \\
\hline Pressure (atm) & 1 & 0.2 \\
\hline Solvent feed stage & 3 & ------- \\
\hline Solvent to Feed ratio $(\mathrm{S} / \mathrm{F})$ & 0.3 & -------- \\
\hline $\mathrm{CaCl}_{2}$ concentration $(\mathrm{g} / \mathrm{ml}$ solvent $)$ & 0.075 & ------- \\
\hline Energy consumption $(\mathrm{kJ} / \mathrm{kg}$ ethanol) & 1204 & 221 \\
\hline Recovered energy in stream $7(\mathrm{~kJ} / \mathrm{kg}$ ethanol) & \multicolumn{2}{|c|}{111} \\
\hline Net energy consumption $(\mathrm{kJ} / \mathrm{kg}$ ethanol) & \multicolumn{2}{|c|}{1425} \\
\hline
\end{tabular}

Table 2: Material balance for the extractive distillation process

\begin{tabular}{|l|c|c|r|r|r|r|r|r|r|r|}
\hline Stream & $\mathbf{1}$ & $\mathbf{2}$ & \multicolumn{1}{|c|}{$\mathbf{3}$} & \multicolumn{1}{|c|}{$\mathbf{4}$} & \multicolumn{1}{|c|}{$\mathbf{5}$} & \multicolumn{1}{|c}{$\mathbf{6}$} & $\mathbf{7}$ & $\mathbf{8}$ & $\mathbf{9}$ & $\mathbf{1 0}$ \\
\hline Temperature $\left({ }^{\circ} \mathrm{C}\right)$ & 50,000 & 78,189 & 78,350 & 120,990 & 47,877 & 149,984 & 150,013 & 80,000 & 80,000 & 79,982 \\
Pressure (bar) & 1,013 & 1,013 & 1,013 & 1,013 & 0,202 & 0,202 & 1,013 & 1,013 & 1,013 & 1,013 \\
Molar flow (kmol/h) & & & & & & & & & \\
Water & 11,000 & 11,000 & 0,283 & 10,723 & 10,717 & 0,005 & 0,005 & 0,005 & - & 0,005 \\
Ethanol & 89,000 & 89,000 & 86,546 & 2,454 & 2,454 & 0,000 & 0,000 & 0,000 & - & 0,000 \\
Ethylene glycol & - & - & 0,036 & 29,964 & 0,534 & 29,430 & 29,430 & 29,430 & 0,570 & 30,000 \\
Calcium chloride & - & - & 0,000 & 1,201 & 0,000 & 1,201 & 1,201 & 1,201 & - & 1,201 \\
Total molar flow (kmol/h) & 100,000 & 100,000 & 86,864 & 44,343 & 13,706 & 30,637 & 30,637 & 30,637 & 0,570 & 31,207 \\
Total mass flow $(\mathrm{kg} / \mathrm{h})$ & $4.298,3$ & $4.298,3$ & $3.994,4$ & $2.299,4$ & 339,3 & $1.960,1$ & $1.960,1$ & $1.960,1$ & 35,4 & $1.995,5$ \\
\hline
\end{tabular}

Table 3: Energy consumption for ethanol dehydration technologies

\begin{tabular}{|c|c|c|}
\hline Process type & $\begin{array}{c}\text { Feed Molar } \\
\text { Composition }\end{array}$ & $\begin{array}{l}\mathrm{kJ} / \mathrm{kg} \text { of } \\
\text { ethanol }\end{array}$ \\
\hline Process studied & $88 \%$ ethanol & 1425 \\
\hline Azeotropic distillation with benzene (Chianese and Zinnamosca, 1990) & $85 \%$ ethanol & 4853 \\
\hline Extractive distillation with ethylene glycol-potassium acetate $(\mathrm{Fu}, 2004 \mathrm{~b})$ & $88 \%$ ethanol & 3580 \\
\hline Extractive distillation with ethylene glycol (Meirelles et al., 1992) & $85 \%$ ethanol & 1760 \\
\hline Extractive distillation with gasoline (Chianese and Zinnamosca, 1990) & $85 \%$ ethanol & 3180 \\
\hline Adsorption with molecular sieves (Jacques et al., 1999) & $88 \%$ ethanol & 1430 \\
\hline
\end{tabular}

\section{CONCLUSIONS}

The thermodynamic model chosen fits properly the experimental vapor-liquid equilibrium data for the mixture studied. Thereby, the simulation results were supported on a solid thermodynamic basis, which can describe the mixture behavior in a very accurate way.

This work made possible to establish operating conditions for an extractive distillation process using salt and solvent. Reflux ratio has the greatest effect on energy consumption, and it must be operated at low values, together with an entry solvent temperature between 70 and $90^{\circ} \mathrm{C}$. In the same way, it is concluded that $\mathrm{S} / \mathrm{F}$ ratio is a useful variable for compensating changes in operating conditions of the column, and that can be used to obtain high ethanol concentrations in the overhead product, without implying in important energy consumption. To sum up, it was found that extractive distillation is a process energetically competitive with respect to other technologies, as it is shown in Table 3. Comparing energy consumption reports, it is found the lowest energy consumption values are for molecular sieves and extractive distillation with ethylene glycol technologies, what makes them competitive and an appealing subject of research and implementation. As it was previously mentioned, the technology using molecular sieves presents low energy consumption, but it spends additional energy 
for redistill the alcohol recycle generated by the operation (Jacques et al. 1999). Additionally, ethanol obtained by extractive distillation with salt and solvent as entrainer is comparable with the former obtained by adsorption with molecular sieves in terms of quality, taking into account that the content of ethylene glycol in the final product is lower than the minimal required $(0.1 \% \mathrm{w} / \mathrm{w} \max )$ and the salt is not present. In this way, anhydrous ethanol produced by this method is suitable for several applications like chemical synthesis of esters, organic and cyclic compound chains, detergents, paints, cosmetics, aerosols, among others.

\section{ACKNOWLEDGEMENTS}

This work was supported financially by research grants from Research Division of the National University of Colombia (DIB) (project 1064 from August 2003) and Colciencias by financial support of research project code: 110106-14844.

\section{REFERENCES}

Barba, D., Brandani, V., \& di Giacomo, G. Hyperazeotropic ethanol salted-out by extractive distillation. Theorical evaluation and experimental check. Chemical Engineering Science. 40 (1985) 2287-2292.

Black, C., \& Distler, D. E. Dehydration of aqueous ethanol mixtures by extractive distillation. In: R.F. Gould, Extractive and azeotropic distillation, Advances in Chemistry Series 115 (1972) 1-15.

Black, C. Distillation modeling of ethanol recovery and dehydration processes for ethanol and gasohol. Chemical Engineering Progress 76 (1980) 78-85.

Chianese, A., \& Zinnamosca, F. Ethanol dehydration by azeotropic distillation with mixed solvent entrainer. The Chemical Engineering Journal 43 (1990) 59-65.

$\mathrm{Fu}$, J. Simulation of Salt-Containing Extractive Distillation for the System of Ethanol/Water/ Ethanediol/KAc. 1. Calculation of the VaporLiquid Equilibrium for the Salt-Containing System. Industrial and Engineering Chemical Research 43 (2004) 1274-1278.

$\mathrm{Fu}$, J. Simulation of Salt-Containing Extractive Distillation for the System of Ethanol/Water/ Ethanediol/KAc. 2. Simulation of Salt Containing
Extractive Distillation. Industrial and Engineering Chemical Research 43 (2004) 1279-1283.

Furter, W. F. Extractive distillation by salt effect. Chemical Engineering Communications 116 (1992) 35-40.

Jacques, K., Lyons, T. P. \& Kelsall, D. R. Alcohol Textbook. Nottingham University Press, 1999.

Lee, F., \& Pahl, R. H. (Solvent screening study and conceptual extractive distillation process to produce anhydrous ethanol from fermentation broth. Industrial Engineering Chemical Process Des. Dev 24 (1985) 168-172.

Ligero, E.L., \& Ravagnani, T.M.K. Dehydration of ethanol with salt extractive distillation - a comparative analysis between processes with salt recovery. Chemical Engineering and Processing 42 (2003) 543-552.

Llano, M., \& Aguilar, J. Modeling and simulation of saline extractive distillation columns for the production of absolute ethanol. Computers and Chemical Engineering 27 (2003) 527-549.

Lynn, S., \& Hanson, D.N. Multieffect extractive distillation for separating aqueous azeotropes. Industrial Engineering Chemical Process Des. Dev 25 (1988) 936-941.

Meirelles, A., Weiss, S., \& Herfurth, H. Ethanol dehydration by extractive distillation. Journal of Chemical Technology \& Biotechnology 53 (1992) 181-188.

Perry, R. Chemical Engineer's Handbook, $7^{\text {th }}$ ed., McGraw-Hill, New York, 1992.

Pinto, R. T. P., Wolf-Maciel, M. R., \& Lintomen, L. Saline extractive distillation process for ethanol purification. Computers and Chemical Engineering 24 (2000) 1689-1694.

Rongqi, Z., \& Zhanting, D. Extractive Distillation with Salt in Solvent. Science and Technology. (1999).

Schmit, D., \& Vogelpohl, A. Distillation of ethanolwater solutions in the presence of potassium acetate. Separation science and technology 18 (1983) 547-554.

Stupiello, J. Aspectos técnicos para tener en cuenta en las etapas de fermentación y destilación en la producción de alcohol. In: Memorias Seminario de Alcohol Carburante. June Cali, Colombia, 2003.

Ulrich, S., \& Pavel, S. Design and operation of a pervaporation plant for ethanol dehydration. Journal of membrane science 36 (1988) 463-475.

Zhigang, L., Hongyou, W., Rongqi, Z., \& Zhanting, D. Influence of salt added to solvent on extractive distillation. Chemical Engineering Journal 87 (2002) 149-156. 